\title{
THE IMPACT OF PROFESSIONAL STATUS ON THE EFFECTS OF AND ADHERENCE TO THE OUTPATIENT FOLLOWED BY HOME-BASED TELEMONITORED CARDIAC REHABILITATION IN PATIENTS REFERRED BY A SOCIAL INSURANCE INSTITUTION
}

\section{DOMINIKA SZALEWSKA, PIOTR NIEDOSZYTKO, and KATARZYNA GIERAT-HAPONIUK}

\author{
Medical University of Gdańsk, Gdańsk, Poland \\ Department of Rehabilitation
}

\begin{abstract}
Objectives: Legislators and policymakers have expressed strong interest in intervention programs to reduce dependence on social disability benefits. Hybrid: ambulatory followed by home-based cardiac telerehabilitation - hybrid cardiac rehabilitation (HCR) seems to be a novel alternative for standard cardiac rehabilitation for patients with cardiovascular diseases (CVD) as a form of pension prevention paid by the Social Insurance Institution (SII). The kind of professional status may bias the motivation to return to work after HCR. The aim of our study was to evaluate whether the professional status can affect the effects of HCR. Material and Methods: One hundred fifty-two patients with CVD referred by the SII for a 5-week HCR were qualified for the study. Patients $(87.7 \%$ males), aged $57.31 \pm 5.61$ years, were divided into 2 subgroups: $\mathrm{W})$ white-collar employees $(\mathrm{N}=22)$ and $\mathrm{B})$ blue-collar employees $(\mathrm{N}=130)$. To evaluate functional capacity, an exercise test on a treadmill was used. Results: The number of days of absence in the cardiac rehabilitation program did not differ between the groups (mean \pm standard deviation $-\mathrm{B}: 1.09 \pm 3.10$ days, W: $1.95 \pm 3.64$ days). There were significant improvements $(\mathrm{p}<0.05)$ in measured variables after HCR in both (W and $\mathrm{B})$ groups (max workload: 8.21 \pm 2.88 METs (measured in metabolic equivalents) vs. 9.6 \pm 2.49 METs, 7.76 \pm 2.51 METs vs. 8.73 \pm 2.7 METs, resting heart rate (RHR): $77 \pm 16.22$ bpm vs. $69.94 \pm 12.93$ bpm, $79.59 \pm 14$ bpm vs. $75.24 \pm 11.87$ bpm; double product, i.e., product of heart rate and systolic BP (DP rest) $10815.22 \pm 2968.24$ vs. $9242.94 \pm 1923.08,10927.62 \pm 2508.47$ vs. $9929.7 \pm 2304.94$ ). In group B, a decrease in systolic blood pressure (BP syst. $-137.03 \pm 17.14 \mathrm{~mm} \mathrm{Hg}$ vs. $131.82 \pm 21.13 \mathrm{~mm} \mathrm{Hg}$ ), heart rate recovery in the 1st minute after the end of peak exercise $\left(\mathrm{HRR}_{1}\right)(99.38 \pm 19.25$ vs. $93.9 \pm 19.48)$ and New York Heart Association (NYHA) class $(1.22 \pm 0.53$ vs. $1.11 \pm 0.36)$ was observed. In group W, a decrease in diastolic blood pressure (BP diast.) at rest was observed $(88.28 \pm 9.79 \mathrm{~mm} \mathrm{Hg}$ vs. $83.39 \pm 8.95 \mathrm{~mm} \mathrm{Hg})$. The decrease in resting HR was significantly greater in group W $(69.94 \pm 12.93$ vs. $75.24 \pm 11.87, p=0.034)$. Conclusions: Hybrid cardiac rehabilitation is feasible and safe with high adherence to the program regardless of the patient's professional status. Professional status did not influence the beneficial effect of HCR on exercise tolerance.
\end{abstract}

Key words:

Rehabilitation, Coronary artery disease, Telemedicine, Cardiac rehabilitation, Social benefit, Occupational status

Received: October 22, 2014. Accepted: April 13, 2015.

Corresponding author: D. Szalewska, Medical University of Gdańsk, Department of Rehabilitation, Dębinki 7, 80-211 Gdańsk, Poland (e-mail: dziel@gumed.edu.pl). 


\section{INTRODUCTION}

Legislators and policymakers have expressed strong interest in early intervention programs to reduce dependence on social disability benefits. The continuing rise in the number of individuals enrolled in the Polish Social Insurance Institution (SII) and growing expenditures paid out to beneficiaries have prompted the need to identify strategies that will limit the growth of future outlays. Since 2008, an increase in the nominal benefit payments expenditure has been observed.

Expenditure in the area served by the SII includes expenditure on disability payments for incapacity for work including care allowances; expenditure on social pensions, paid from the state budget; expenditure on sickness absence, meaning temporary inability to work due to sickness itself (sick leave); sickness benefits; expenditure on social rehabilitation benefits; and expenditure on medical rehabilitation under the SII pension prevention policy. The amount of these expenses during 2012 accounted for $1.9 \%$ of Poland's gross domestic product (GDP). The highest percentage of expenditure on benefits associated with the inability to work was spent on pensions for incapacity for work. In the structure of total expenditure on benefits for incapacity for work in 2012, cardiovascular diseases were in 2 nd place in terms of generating costs and accounted for $15.1 \%$ of total costs [1].

Home-based rehabilitation is a novel and less expensive alternative for patients with cardiovascular diseases, and in Poland has also been used in the rehabilitation of people with musculoskeletal diseases and in patients with hearing and speech disorders [2]. Cardiac telerehabilitation is based on physical exercise performed at home under the supervision of a specialist center. For the first time, the SII implemented a home-based program of cardiac telerehabilitation in 2009, initially as a pilot program.

Introducing hybrid: ambulatory followed by home-based cardiac telerehabilitation (hybrid cardiac rehabilitation - HCR) may eliminate most of the factors that result in the currently low number of patients undergoing outpatient-based rehabilitation programs and may be more attractive for vocationally active patients [3-4]. To date, only a few studies have demonstrated favorable effects of telemonitored cardiac rehabilitation (CR) in patients with stable heart diseases in phase III of CR, the main goal of which is to strive for sustainable, beneficial lifestyle changes that patients will continue after completion of the program, education and assistance in quitting addictions. The population assessed in this study is unique because it comprises only patients suffering from cardiovascular diseases who do not work due to disability payment, social rehabilitation benefit and sick leave. The aim of the study was to evaluate whether professional status can affect the effects of the hybrid (ambulatory followed by home-based cardiac) telerehabilitation in patients referred by a social insurance institution.

The secondary end point was the assessment of the adherence to this kind of treatment.

\section{MATERIAL AND METHODS}

This was a retrospective 1-institutional cohort study that comprised patients referred for home-based cardiac telerehabilitation by the Polish Social Insurance Institution (SII).

\section{Patient population}

A total of 155 patients were referred by the SII for outpatient followed by home-based telemonitored cardiac rehabilitation, phase III CR, from January 2010 to December 2013. From this group, 3 patients who did not begin training for the following reasons - deep vein thrombosis, lumbar sciatica and back pain due to discopathy - were excluded from the analysis. Finally, 152 patients with documented cardiovascular diseases (CVD) referred by the SII for a 5-week HCR were qualified for the study. Patients $(87.7 \%$ males), aged $57.31 \pm 5.61$ years (mean \pm standard deviation), were divided into 2 subgroups: group 
$\mathrm{W}$ - white-collar employees $(\mathrm{N}=22)$, and group $\mathrm{B}$ - bluecollar employees $(\mathrm{N}=130)$. White-collar employees were defined as people who performed professional, managerial or administrative work, and worked in an office or cubicle, while blue-collar workers were defined as people whose job required manual labor. Cardiac rehabilitation began no sooner than 12 weeks following the cardiovascular event.

\section{Study protocol}

The study was designed as a retrospective non-randomized trial. The patients underwent the following assessments at entry and after completing HCR - a physical examination, an exercise treadmill test according to the Bruce protocol and additional laboratory tests when it was necessary to assess their clinical state. Adherence was reported as the number of dropouts during the whole HCR program.

\section{Exercise test}

All patients underwent a symptom-limited exercise test (ET) performed according to the Bruce protocol [5] on a Woodway treadmill, using a computerized electrocardiography (ECG) Sun Tech Tango system. Twelve standard electrocardiographic leads were continuously recorded before, during and for $10 \mathrm{~min}$ after the test. Patients were encouraged to exercise to their maximum.

The test was discontinued in the case of reported anginal chest pain, maximal fatigue, arterial blood pressure increase over 230/120 mm Hg, ST segment depression by at least $2 \mathrm{~mm}$ in ECG, or severe arrhythmia. The following parameters were analyzed: max workload (measured in metabolic equivalents - METs), heart rate in beats per min (HR, bpm) at rest and at peak effort, blood pressure $(\mathrm{BP}, \mathrm{mm} \mathrm{Hg}$ ) at rest and at peak effort, and double product (DP, $\mathrm{mm} \mathrm{Hg} / \mathrm{min} \times 100$ ), e.g., the product of HR and systolic BP at rest and at peak effort [6]. Heart rate recovery in the 1st minute after the end of peak exercise $\left(\mathrm{HRR}_{1}\right)$ was measured as the method to assess the reactivation of the parasympathetic nervous system.

\section{Hybrid cardiac telerehabilitation}

Hybrid cardiac rehabilitation prescription followed the guidelines of cardiac rehabilitation and comprised all core components: medical evaluation, exercise training, relaxation sessions, educational, counselling, and behavioral interventions and other secondary prevention strategies for risk factor reduction [7]. All patients received remote-controlled equipment for tele-ECG monitoring and supervised exercise training (Pro Plus Company, Poland). The device enabled ECG data to be recorded using 3 precordial leads and transmitted via a mobile phone network to the monitoring center, which was located in the department of rehabilitation. Hybrid cardiac rehabilitation consisted of 2 phases: an ambulatory phase, conducted within an outpatient rehabilitation center (8-10 days), and a home-based phase, conducted at home (11-12 days).

The goals of the 1st stage were: a baseline clinical examination, optimization of pharmacological treatment, education in the prevention of cardiovascular risk factors and coping with stress, individual planning of exercise training, psychological assessment and relaxation sessions. The home-based stage comprised the training consent procedure, which included a telephone conversation with a physician during which the patient answered questions about her/his present clinical condition, symptoms and medications taken and was asked to send resting and the training session ECG data.

The telemonitoring system had details of the training sessions and times of automatic ECG recording preprogrammed for each patient. If the training session was completed uneventfully, the patient transmitted the ECG recording via the mobile phone to the monitoring center at the end of the session. Exercise training was planned individually for each patient according to the published guidelines [7]. The training HR was calculated using the HR 
reserve method (Karvonen's method), based on data obtained in the exercise test. This method uses the heart rate reserve to calculate training zones based on both maximum and resting heart rate [8].

The target training HR was $60-80 \%$ of the HR reserve. Each training session consisted of 3 parts: 1st, warming up lasting 5-10 min, comprising breathing exercises, light resistance and systemic exercises; $2 \mathrm{nd}$, aerobic endurance training based on different forms, i.e., either walking or Nordic walking or cycloergometer training for $30 \mathrm{~min}$ each; and finally a 5-10 min cooling down period. Patients were trained 5 times a week. The technical details of the telemonitoring system were presented previously by Piotrowicz et al. [3].

\section{ETHICS}

The procedures followed were in accordance with the ethical standards of a responsible institutional committee on human experimentation and with the Helsinki Declaration of 1975 , as revised in 1983 [9]. Each patient gave a written, institutional informed consent for participation in the program.

\section{STATISTICS}

The collected data were analyzed using IBM SPSS version 21. To compare the baseline characteristics of group $\mathrm{W}$ and group $\mathrm{B}$, the Fisher test was used because of the small size of the groups. Student's t-tests were performed to test the independent and dependent samples for normally distributed variables, and the Wilcoxon and Mann-Whitney tests for variables not distributed normally in the analysis of the effects of cardiac rehabilitation. $\mathrm{P}<0.05$ was considered significant.

\section{RESULTS}

\section{Baseline characteristics}

One hundred and thirty patients (114 men, 16 women) with a mean age of $57.16 \pm 5.69$ years from group B and 22 patients (19 men, 3 women) with a mean age of $58.23 \pm 4.97$ years from group $\mathrm{W}$ were qualified for analysis. To compare sex, age and the mean number of absences in the HCR program, the Mann-Whitney test was used due to the large differences in group size. No statistical differences were found. To compare the distribution of other variables, the exact Fisher test was used because of the small size of the groups.

The most frequent kinds of disability benefit were social rehabilitation benefit and disability payment in both groups ( $p=0.157$ ). Blue-collar employees were current smokers $(p=0.09)$ or had a smoking history $(p=0.01)$ more frequently than white-collar workers. Hyperlipidemia also occurred in blue-collar workers more frequently $(\mathrm{p}=0.035)$. The baseline clinical and demographic characteristics of the patients are summarized in Table 1.

\section{Adherence}

The number of days of absence in the cardiac rehabilitation program did not differ between the groups. The mean number of days of absence was $1.09 \pm 3.1$ days in group B and $1.95 \pm 3.64$ days in group $\mathrm{W}$.

No tested subjects were excluded from home-based training or finished the training earlier for major adverse cardiac events (MACE) or other cardiovascular reasons.

\section{Effects of HCR in white-collar workers and in blue-collar workers}

There were some significant improvements $(\mathrm{p}<0.001)$ in variables measured in the exercise test on a treadmill after HCR. Maximal workload measured in metabolic equivalents (METs) improved significantly $(\mathrm{p}<0.05)$, while resting heart rate and double product decreased significantly in both groups. The effectiveness of HCR in terms of lowering systolic BP at rest $(137.03 \pm 17.14 \mathrm{~mm} \mathrm{Hg}$ before HCR vs. $131.82 \pm 21.13 \mathrm{~mm} \mathrm{Hg}$ after HCR, $\mathrm{p}=0.04)$, lowering $\mathrm{HRR}_{1}(99.38 \pm 19.25 \mathrm{bpm}$ before HCR vs. $93.90 \pm 19.48 \mathrm{bpm}$ after HCR, $\mathrm{p}=0.001)$ and NYHA class $(1.22 \pm 0.53$ vs. $1.11 \pm 0.36, \mathrm{p}<0.01)$ was 
Table 1. Baseline clinical and demographic characteristics of study group - blue-collar (B) and white-collar (W) workers

\begin{tabular}{|c|c|c|c|}
\hline Variable & $\begin{array}{c}\text { Group B } \\
(\mathrm{N}=130)\end{array}$ & $\begin{array}{l}\text { Group W } \\
(\mathrm{N}=22)\end{array}$ & $\mathrm{p}$ \\
\hline Males [n (\%)] & $114(87.7)$ & $19(86.4)$ & 0.740 \\
\hline Age [years] $(\mathrm{M} \pm \mathrm{SD})$ & $57.16 \pm 5.69$ & $58.23 \pm 4.97$ & 0.450 \\
\hline Kind of disability benefit $[\mathrm{n}(\%)]$ & & & 0.157 \\
\hline unemployed & $1(0.8)$ & $0(0.0)$ & \\
\hline disability payment & $39(30.0)$ & $9(40.9)$ & \\
\hline social rehabilitation benefit & $77(59.2)$ & $8(36.4)$ & \\
\hline sick leave & $13(10.0)$ & $5(22.7)$ & \\
\hline Body mass index $(\mathrm{M} \pm \mathrm{SD})$ & $28.81 \pm 4.40$ & $29.62 \pm 4.76$ & 0.214 \\
\hline Days of absence in the cardiac rehabilitation program $[\mathrm{n}](\mathrm{M} \pm \mathrm{SD})$ & $1.09 \pm 3.10$ & $1.95 \pm 3.64$ & 0.200 \\
\hline Current smoker $[\mathrm{n}(\%)]$ & $31(25.6)$ & $0(0.0)$ & 0.009 \\
\hline Smoking history $[\mathrm{n}(\%)]$ & $99(83.2)$ & $10(50.0)$ & 0.001 \\
\hline Coronary artery disease $[\mathrm{n}(\%)]$ & $106(81.5)$ & $17(77.3)$ & 0.640 \\
\hline Myocardial infarction $[\mathrm{n}(\%)]$ & $76(58.5)$ & $12(54.5)$ & 0.730 \\
\hline Heart failure $[\mathrm{n}(\%)]$ & $16(12.3)$ & $3(13.6)$ & 0.740 \\
\hline Percutaneous coronary intervention $[\mathrm{n}(\%)]$ & $76(58.5)$ & $11(50)$ & 0.171 \\
\hline Coronary artery bypass grafting $[\mathrm{n}(\%)]$ & $20(15.4)$ & $6(27.3)$ & 0.111 \\
\hline Arterial hypertension $[\mathrm{n}(\%)]$ & $110(84.6)$ & $18(81.8)$ & 0.750 \\
\hline Atrial fibrillation chronic or persistent $[\mathrm{n}(\%)]$ & $7(5.4)$ & $1(4.5)$ & 1.000 \\
\hline Chronic obstructive pulmonary disease $[\mathrm{n}(\%)]$ & $6(4.6)$ & $0(0.0)$ & 0.304 \\
\hline Hyperlipidemia [n (\%)] & $63(48.5)$ & $5(22.7)$ & 0.035 \\
\hline Obesity $[\mathrm{n}(\%)]$ & $58(45.0)$ & $8(36.4)$ & 0.450 \\
\hline Overweight $[\mathrm{n}(\%)]$ & $58(45.0)$ & $10(45.5)$ & 0.966 \\
\hline Ca-blocker $[\mathrm{n}(\%)]$ & $30(23.8)$ & $7(33.3)$ & 0.350 \\
\hline Beta-blocker [n (\%)] & $115(92.0)$ & $17(81.0)$ & 0.112 \\
\hline Angiotensin converting enzyme inhibitors [ $\mathrm{n}(\%)]$ & $86(68.8)$ & $12(57.1)$ & 0.293 \\
\hline Clopidogrel / Dabigatran [n (\%)] & $51(40.8)$ & $5(23.8)$ & 0.138 \\
\hline Inhibitor PP [n (\%)] & $49(39.5)$ & $4(19.0)$ & 0.072 \\
\hline Aspirin $[\mathrm{n}(\%)]$ & $99(79.2)$ & $14(66.7)$ & 0.258 \\
\hline Statins $[\mathrm{n}(\%)]$ & $108(87.1)$ & $16(76.2)$ & 0.191 \\
\hline Loop diuretics $[\mathrm{n}(\%)]$ & $10(8.0)$ & $2(9.5)$ & 0.684 \\
\hline Oral anticoagulants $[\mathrm{n}(\%)]$ & $12(9.6)$ & $5(23.8)$ & 0.073 \\
\hline Insulin therapy $[\mathrm{n}(\%)]$ & $7(5.6)$ & $1(4.8)$ & 1.000 \\
\hline Oral glucose-lowering agents $[\mathrm{n}(\%)]$ & $25(20.0)$ & $8(38.1)$ & 0.089 \\
\hline
\end{tabular}

$\mathrm{M}$ - mean; SD - standard deviation; PP - proton pump. 
significant in group B. Diastolic BP at rest decreased significantly only in group W $(88.28 \pm 9.79 \mathrm{~mm} \mathrm{Hg}$ before vs. $83.39 \pm 8.95 \mathrm{~mm} \mathrm{Hg}$ after HCR). The results of the exercise stress test are summarized in Table 2.

\section{Comparison of exercise test results}

between white-collar and blue-collar workers

Baseline heart rate decreased significantly after HCR in white-collar patients in comparison with blue-collar patients (Figure 1$)$ and $\mathrm{HRR}_{1}$ had a tendency $(\mathrm{p}=0.062)$ to be lower in this group. Other results of exercise test did not differ between groups. Comparison of exercise test results between white-collar employees (group W) and blue-collar employees (group B) before and after HCR is shown in Table 3.

\section{DISCUSSION}

The main conclusion from this study was that adherence to the HCR program in the group of patients with CVD referred by the SII was high and the effects of training were comparable regardless of the type of work. The effectiveness and safety of hybrid cardiac telerehabilitation has been proved previously; a positive opinion in terms of the ability to return to professional work has been given by as many as $93 \%$ of patients [10]. The motivation to return to work and at the same time the effects of cardiac rehabilitation may be different according to the type of work. Some authors proved that lower income may hinder the use of sick leave by blue-collar employees as these employees are most vulnerable to the loss of income [11]. This factor, but also social and sickness benefits from the illness, can bias the effects of HCR.

In this study the difference in the size of study groups was substantial: most of the participants were blue-collar workers, but this was not surprising in the light of epidemiological studies. The EUROASPIRE II (European Action on Secondary and Primary Prevention through Intervention to Reduce Events) substudy [12], for example, showed

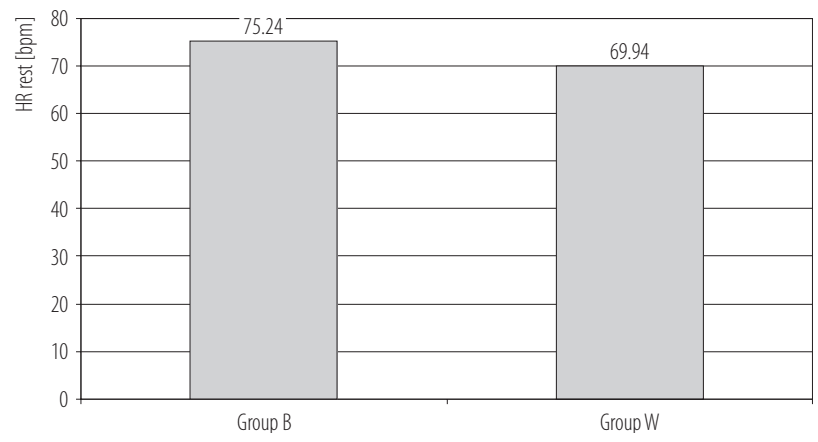

HR - heart rate. $\mathrm{p}=0.034$.

Fig. 1. Mean resting heart rate after hybrid cardiac rehabilitation (HCR) in blue-collar (group B) and white-collar (group W) workers

that patients with higher education, which is often associated with white-collar employment, had significantly lower global coronary risk than people with lower education.

Moreover, significantly more patients with ischemia had only primary education. In this huge, multicentre survey, which comprised data for 5556 individuals (1319 women), Poland took part as one of 15 European countries. Generally, socioeconomic status (SES), a very complex phenomenon predicted by a broad range of variables mainly combining the influences of education and occupation, is believed to be associated with development of coronary artery disease (CAD) [13].

Another important issue is that among the occupational factors that influence the decision to retire early, hard physical work, high physical demands, low degree of job control and low job satisfaction are frequently mentioned [14-17]. The implementation of telerehabilitation programs in cardiology, especially in patients with $\mathrm{CAD}$, is a very important alternative to traditional forms of rehabilitation whether stationary or ambulatory, and is also used to intensify medical actions targeting people temporarily unable to work.

It seems that ECG monitoring at home encourages good compliance, which was also observed in patients with 

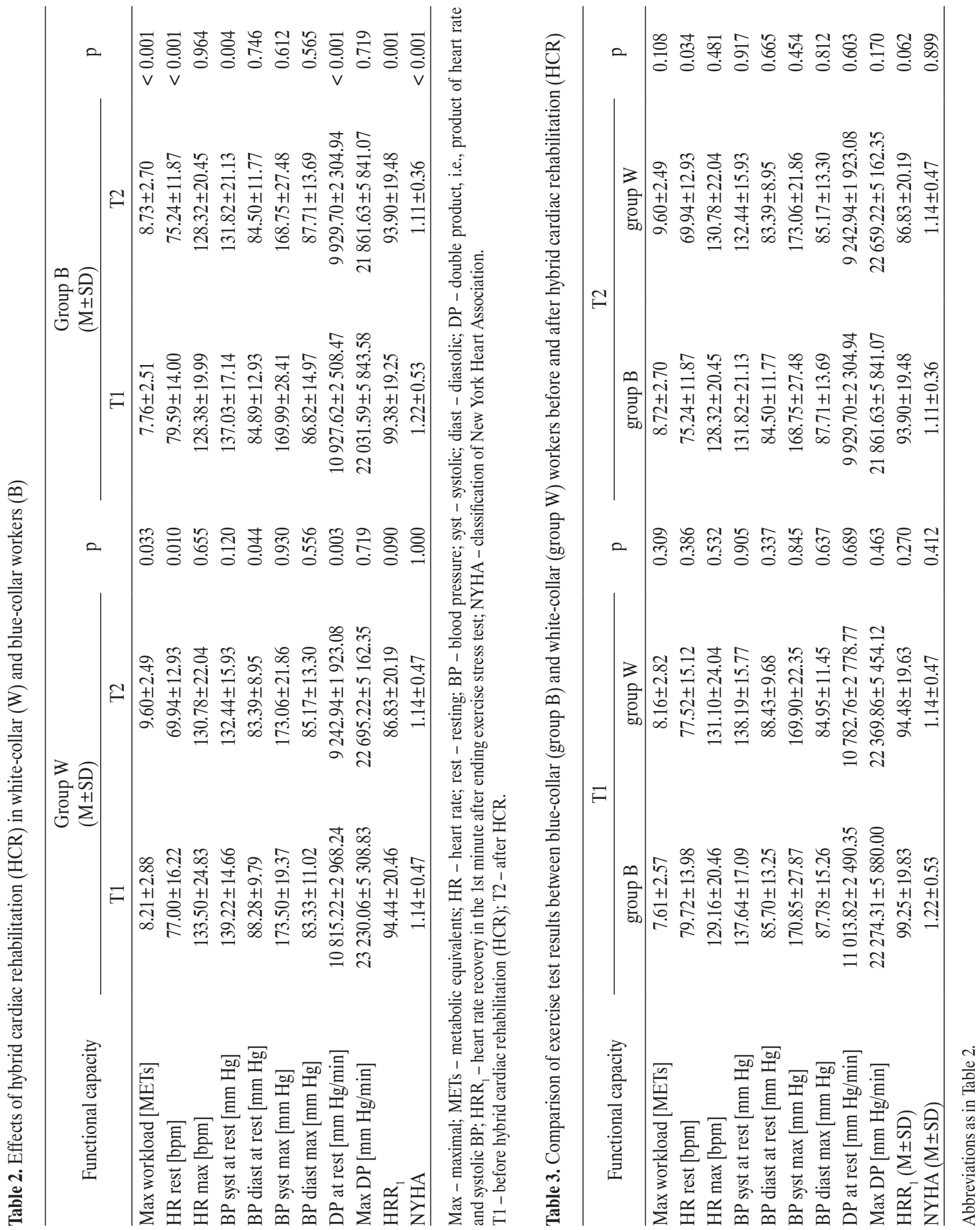
cardiovascular diseases rehabilitated by a similar method and even in heart failure patients who performed Nordic walking as a form of aerobic training [4]. One of the goals of CR is to facilitate return to a social and professional life as similar as possible to that which the patients had before their cardiac events [18] and one of the aims of the SII is to help patients with cardiovascular diseases to achieve this through disability prevention programs.

In our study, patients took part in phase III of CR, which means that they had not been working for at least 6 months. Physical capacity in the meaning of the increase of maximal workload, decrease of resting heart rate and double product improved significantly regardless of the patient's professional status. The greater decrease in resting heart rate in white-collar patients than in blue-collar ones and the significant reduction of diastolic blood pressure at rest was the significant difference between the effectiveness of HCR of the 2 groups.

As adherence to the rehabilitation program was good in both groups of patients and the medical treatment was not modified during HCR, the explanation of this phenomenon may be sought in the better efficiency of educational, tailored counselling and behavioral interventions in group W. The impact of professional status on the rehabilitation outcomes in patients with CVD has been poorly investigated by other authors so far; we may only speculate that the relation mentioned above actually exists.

Hybrid cardiac rehabilitation is a comprehensive procedure that includes all core components of $\mathrm{CR}$ according to guidelines: exercise training, education, psychological counselling, relaxation sessions and other secondary prevention strategies for risk factor modification [7]. Certainly, greater emphasis should be placed on education in a group of bluecollar workers as they were more frequently current smokers than white-collar workers, and had a smoking history and hyperlipidemia, although other authors showed little evidence that the occupational characteristics accelerated the progression of subclinical CVD [19]. Inoue et al. found a positive association among blue-collar workers between shift work and hypertension [20].

A strong need for new, efficient and effective interventions to support the growing number of people living on social benefits and the international interest in using new technologies such as the Internet, text messaging, telephone support or remote monitoring to help patients manage longterm conditions and help in returning to work is observed by many authors. A randomized controlled prospective clinical trial which aims to evaluate the effectiveness and cost-effectiveness of a telehealth intervention to support patients with long-term health condition and another one comparing home-based training with telemonitoring guidance versus center-based training in patients with $\mathrm{CAD}$ in the maintenance phase are being conducted now [21,22]. The method selected by the Polish Social Insurance Institution - hybrid cardiac telerehabilitation - is a safe form of helping patients to return to work after the onset of cardiovascular disease, regardless of the professional status.

\section{CONCLUSIONS}

Hybrid cardiac rehabilitation is feasible and safe with high adherence to the program regardless of the patient's professional status.

Professional status did not influence the beneficial effect of hybrid cardiac rehabilitation on exercise tolerance.

\section{REFERENCES}

1. Social Insurance Institution. The structure of pensions and disability payments [cited 2014 Oct 2]. Available from: http:// zus.pl/default.asp? $\mathrm{p}=5$ \&id.

2. Wierzyńska B. [Telerehabilitation]. Prew Rehab. 2013;(1): 7-10. Polish.

3. Piotrowicz E, Korzeniowska-Kubacka I, Chrapowicka A, Wolszakiewicz J, Dobraszkiewicz-Wasilewska B, Batogowski M, et al. Feasibility of home-based cardiac telerehabilitation: Results of TeleInterMed study. Cardiol J, http://dx.doi. org/10.5603/CJ.a2014.0005. 
4. Piotrowicz E, Baranowski R, Bilińska M, Stepnowska M, Piotrowska M, Wójcik A, et al. A new model of homebased telemonitored cardiac rehabilitation in patients with heart failure: Effectiveness, quality of life, and adherence. Eur J Heart Fail. 2010;12:164-71, http://dx.doi.org/10.1093/ eurjhf/hfp181.

5. Bruce RA, Kusumi F, Hosmer D. Maximal oxygen intake and nomographic assessment of functional aerobic impairment in cardiovascular disease. Am Heart J. 1973;85:546, http://dx.doi.org/10.1016/0002-8703(73)90502-4.

6. Fletcher GF, Balady GJ, Amsterdam EA, Chaitman B, Eckel R, Fleg J, et al. Exercise standards for testing and training. A statement for healthcare professionals from the American Heart Association. Circulation. 2001;104:1694-740, http:// dx.doi.org/10.1161/hc3901.095960.

7. Piepoli MF, Corra U, Benzer W, Bjarnason-Wehrens B, Dendale P, Gaita D, et al. Secondary prevention through cardiac rehabilitation: From knowledge to implementation. A position paper from the Cardiac Rehabilitation Section of the European Association of Cardiovascular Prevention and Rehabilitation. Eur J Cardiovasc Prev Rehabil. 2010;17:1-17, http://dx.doi.org/10.1097/HJR.0b013e 3283313592 .

8. Goldberg L, Elliot DL, Kuehl KS. Assessment of exercise intensity formulas by use of ventilatory threshold. Chest. 1988;94:95-8, http://dx.doi.org/10.1378/chest.94.1.95.

9. Carlson RV, Boyd KM, Webb DJ. The revision of the Declaration of Helsinki: Past, present and future. Br J Clin Pharmacol. 2004;57(6):695-713.

10. Korzeniowska-Kubacka I, Bilińska M, DobraszkiewiczWasilewska B, Piotrowicz R. Comparison between hybrid and standard centre-based cardiac rehabilitation in female patients after myocardial infarction: A pilot study. Kardiol Pol. 2014;72(3):269-74, http://dx.doi.org/10.5603/ KP.a2013.0283.

11. Aaviksoo E, Kiivet RA. Sickness benefit cuts mainly affect blue-collar workers. Scand J Public Health. 2014 Jun 6;42 (6):497-503, http://dx.doi.org/10.1177/1403494814538559.
12. Mayer O Jr., Simon J, Heidrich J, Cokkinos DV, de Bacquer D; EUROASPIRE II study group. Educational level and risk profile of cardiac patients in the EUROASPIRE II substudy. J Epidemiol Community Health. 2004;58:47-52， http://dx.doi.org/10.1136/jech. 58.1.47.

13. Winkleby MA, Jatulis DE, Frank E, Fortmann SP. Socioeconomic status and health: How education, income, and occupation contribute to risk factors for cardiovascular disease. Am J Public Health. 1992;82:816-20, http://dx.doi. org/10.2105/AJPH.82.6.816.

14. Bugajska J, Łastowiecka E. Analysis of total work inability in Poland in 2000 and 2001 according to age, disease diagnosis and occupation. Int J Occup Saf Ergon. 2006;12(3): 231-40, http://dx.doi.org/10.1080/10803548.2006.11076685.

15. Krokstad S, Johnsen R, Westin S. Social determinants of disability pension: A 10-year follow-up of 62000 people in a Norwegian country population. Int J Epidemiol. 2002;31(6):1183-91, http://dx.doi.org/10.1093/ije/31.6.1183.

16. Holte HH, Tambs K, Bjerkedal T. Manual work as predictor for disability pensioning with osteoarthritis among the employed in Norway 1971-1990. Int J Epidemiol. 2000;29(3):487-94, http://dx.doi.org/10.1093/ije/29.3.487.

17. MacDonald LA, Karasek RA, Punnett I, Scharf T. Covariation between workplace physical and psychosocial stressors: Evidence and implication for occupational health and prevention. Ergonomics. 2001;44:696-718, http://dx.doi.org/ 10.1080/00140130119943.

18. Fiabane E, Giorgi I, Candura SM, Argentero P. Return to work after coronary revascularization procedures and a patient's job satisfaction: A prospective study. Int J Occup Med Environ Health. 2015;28(1):52-61.

19. Fujishiro K, Diez Roux AV, Landsbergis P, Kaufman JD, Korcarz CE, Stein JH. Occupational characteristics and the progression of carotid artery intima-media thickness and plaque over 9 years: The Multi-Ethnic Study of Atherosclerosis (MESA). Occup Environ Med 2014, http://dx. doi.org/10.1136/oemed-2014-102311. 
20. Inoue M, Morita H, Inagaki J, Harada N. Influence of differences in their jobs on cardiovascular risk factors in male blue-collar shift workers in their fifties. Int J Occup Environ Health. 2004;10(3):313-8, http://dx.doi.org/10.1179/ oeh.2004.10.3.313.

21. Thomas CL, Man MS, O'Cathain A, Hollinghurst S, Large S, Edwards L, et al. Effectiveness and cost-effectiveness of a telehealth intervention to support the management of long-term conditions: Study protocol for two linked randomized controlled trials. Trials. 2014 Jan 24;15:36, http://dx.doi.org/10.1186/1745-6215-15-36.

22. Avila A, Goetschalckx K, Vanhees L, Cornelissen VA. A randomized controlled study comparing home-based training with telemonitoring guidance versus center-based training in patients with coronary heart disease: Rationale and design of the tele-rehabilitation in coronary heart disease (TRiCH) Study. J Clin Trials. 2014;4:175, http://dx.doi. org/10.4172/2167-0870.1000175.

This work is available in Open Access model and licensed under a Creative Commons Attribution-NonCommercial 3.0 Poland License - http://creativecommons.org/ licenses/by-nc/3.0/pl/deed.en. 